\title{
Intersetorialidade e Estratégia Saúde da Família: tudo ou quase nada a ver?
}

\author{
Intersectoriality and the Family Health Strategy: \\ highly relevant or almost irrelevant?
}

Maria Socorro de Araújo Dias ${ }^{1}$
José Reginaldo Feijão Parente $^{2}$
Maristela Inês Osawa Vasconcelos $^{2}$
Fernando Antônio Cavalcante Dias ${ }^{1}$
${ }^{1}$ Centro de Ciências da Saúde, Universidade Estadual Vale do Acaraú. Av. da Universidade 850, Campus de Betânia. 62040-370 Sobral CE Brasil.

socorroad@gmail.com

2 Escola de Formação em Saúde da Família.

\begin{abstract}
In this study, the understanding of intersectoriality together with the Family Health Strategy (FHS) was analyzed from the perceptions of individuals involved with the social context of primary care in the city of Sobral in the state of Ceará. An analytical study of a qualitative nature was conducted in May 2014. The focal group was the data collection technique with 11 participants chosen for the key functions they perform in their direct interface with the FHS. Data were analyzed using the Lefevre and Lefevre Discourse of the Collective Subject technique (2003). The "word cloud" analysis technique - a graphical way of viewing linguistic data based on Wordle ${ }^{T M}$ software - was also used. Five discourses on intersectoriality were produced: a) the understanding of the group; $b$ ) its importance in the context of the FHS; c) actions performed in the FHS; d) facilitators or obstacles to intersectoriality in the FHS; e) suggestions for enhancing intersectorial cooperation in the FHS. The responses highlighted the complexity of this issue, which requires health managers and professionals to overcome the reductionist model that is derived from a biological perspective on health, the polysemic nature of the term and acknowledging that this is a project under construction.
\end{abstract}

Key words Family health strategy, Intersectoriality, Health promotion
Resumo Neste estudo, analisou-se a compreensão da intersetorialidade com a Estratégia Saúde da Família (ESF), a partir das percepções de sujeitos sociais implicados com o contexto da atenção básica no município de Sobral (CE). Estudo analítico, de natureza qualitativa. Elegeu-se o grupo focal como técnica de coleta de dados, com 11 participantes, escolhidos a partir de funções chaves que exercem na interface direta com a ESF, realizado no mês de maio de 2014. As informações foram analisadas pela técnica do Discurso do Sujeito Coletivo de Lefevre e Lefevre (2003). Utilizou-se também a técnica "nuvem de palavras", criadas a partir do software WordleTM, uma forma gráfica de visualização de dados linguísticos. Foram produzidos 5 discursos sobre intersetorialidade: o entendimento do grupo; sua importância no contexto da ESF; ações realizadas na ESF; facilitadores e dificultadores da intersetorialidade na ESF; sugestões para fortalecimento da intersetorialidade na ESF. As respostas evidenciaram a complexidade desta questão no contexto da ESF, a qual demanda dos gestores e profissionais de saúde a necessidade de superarem o modelo reducionista, que tem a ver com a perspectiva biologicista em saúde, do caráter polissêmico que o termo apresenta e de reconhecerem que se trata de uma proposta em construção.

Palavras-chave Estratégia Saúde da Família, Intersetorialidade, Promoção da saúde 


\section{Introdução}

Nos séculos XVI e XVII, observa-se a ascensão de um modelo de pensamento que deu origem à ciência moderna, influenciando significativamente a forma de ver e agir das gerações subsequentes. Esse modelo, chamado de cartesiano ou mecanicista, teve origem na passagem do paradigma medieval para o moderno ${ }^{1}$.

A modernidade caracteriza-se pela centralidade do homem, que passa a acreditar no poder absoluto da ciência. Por sua vez, elege-se o método científico como condição fundamental para a compreensão e a ação sobre a realidade. A lógica é a de tudo dividir para melhor compreender². Este procedimento vai produzir ao longo do tempo uma série de desdobramentos reducionistas sobre a concepção de mundo e sobre a forma de o homem lidar: consigo mesmo, com os outros homens e com a natureza.

Como consequência desta visão, tem-se a fragmentação do saber, o surgimento das especializações e a dicotomia entre as diversas áreas do saber e da vida. O mundo todo se departamentaliza. Dimensões da vida humana são consideradas isoladamente, isto vale para os campos da saúde, da educação, da economia, das artes, do trabalho. Cada coisa, segmentadamente, adquire vida própria como se isso fosse de fato possível ${ }^{3}$.

A intersetorialidade representa um princípio da Política Nacional de Atenção Básica no Brasil, ao sinalizar como atribuições de todos os profissionais que integram as equipes da Estratégia Saúde da Família, o desenvolvimento de ações intersetoriais por meio de parcerias e de recursos na comunidade que possam potencializar estas ações, além de favorecer a integração de projetos sociais e setores afins orientados para a promoção de saúde 4 .

O exercício da intersetorialidade denota um movimento de superação da visão e das práticas fragmentadas, sendo, ainda, uma estratégia de produção crescente de articulações entre diferentes segmentos, tanto no plano interno quanto no externo $^{5}$.

$\mathrm{Na}$ saúde, este esforço significa reconhecer a complexidade da realidade sanitária e que ações isoladas e descontextualizadas não conseguirão produzir os resultados desejados do ponto de vista de transformação das condições de saúde da população.

Compreende-se aqui que a intersetorialidade implica em reciprocidades dos atores que atuam no contexto da saúde coletiva, o que sugere a ideia de partilhamentos de: significados, conhecimentos, compromissos, valores, afetos, responsabilidades e ações.

É necessário destacar ainda que muitas vezes observam-se práticas multisetoriais que são apresentadas, rotuladas ou interpretadas como se fossem intersetoriais. Nas práticas multisetoriais há apenas a presença de vários setores dedicando-se à resolução de um problema, mas não se observa a questão da reciprocidade. Prevalece a lógica e o ritmo da serialidade, ou seja, há soma de esforços que se sucedem mas não há sinergia. Intersetorialidade implica coparticipação efetiva, ou seja, fazer parte da gestão, da produção e do usufruto compartilhado de algo ou de um processo ${ }^{6}$.

A Estratégia Saúde da Família (ESF) compreende um modelo de atenção à saúde no contexto da Atenção Básica em Saúde, que se estrutura na perspectiva do trabalho de equipes multiprofissionais em um território adstrito desenvolvendo ações a partir do conhecimento da realidade local e das necessidades da população deste território7.

A ESF pretende garantir a aproximação dos profissionais e dos centros de saúde da família da população, promovendo o acesso aos serviços básicos ao possibilitar o estabelecimento de vínculos entre a equipe e os usuários, bem como viabilizar a continuidade do cuidado, e ainda, aumentar, por meio da corresponsabilização da atenção, a capacidade de resolutividade dos problemas de saúde mais comuns, implicando melhores e maiores impacto na situação de saúde local.

O modelo da ESF traz como diretrizes a integralidade e a equidade da atenção, a coordenação e a longitudinalidade do cuidado das famílias e das pessoas sob sua responsabilidade. A organização do trabalho das equipes deve estar centrada nas necessidades dos usuários e na busca contínua de melhoria da qualidade dos serviços ofertados à população.

Desdobra-se desta premissa a indagação: intersetorialidade e Estratégia Saúde da Família: tudo ou nada a ver? Propõe-se problematizar esta pergunta de partida a partir de um diálogo entre a produção científica circulante e os atores que vivenciam o cotidiano da ESF, orientados pela simetrização destes diferentes saberes.

Objetivou-se, portanto, analisar a compreensão da (inter) relação da intersetorialidade com a Estratégia Saúde da Família a partir das percepções de sujeitos sociais implicados com o contexto da atenção básica do município de Sobral (CE). 


\section{Metodologia}

Trata-se de um estudo qualitativo e analítico, no qual se tomou como cenário o Sistema de Saúde de Sobral (CE), com foco na Estratégia Saúde da Família. A cidade de Sobral possui uma população de 203.147 habitantes, com renda per capita de R\$13.501,81 e Índice de Desenvolvimento Humano (IDH) de 0,714. Cerca de 7 mil famílias encontram-se na situação de extrema pobreza ${ }^{8}$. A ESF se organiza a partir de 32 Centros de Saúde da Família com 57 equipes de Saúde da Família, 38 equipes de Saúde Bucal, 6 equipes de Núcleo de Apoio à Saúde da Família, 14 tutores do Sistema Saúde Escola e 52 Residentes em Saúde da Família. O Sistema Saúde Escola compreende uma rede ampliada e descentralizada de processos de aprendizagens formais e não formais no cenário da educação em saúde9. A taxa de cobertura da ESF no município é de $85 \%$ da população. Os participantes foram escolhidos a partir de funções com interface direta com a Estratégia Saúde da Família, a saber: a coordenadora da atenção básica; dois gerentes de Centros de Saúde da Família; a coordenadora do Núcleo de Apoio à Saúde da Família; três tutores do Sistema Saúde Escola de Sobral; e, os seguintes atores vinculados à Residência Multiprofissional em Saúde da Família: a coordenadora, um tutor e dois residentes.

A técnica utilizada para coleta de dados foi o grupo focal, com origem na entrevista grupal. $\mathrm{O}$ termo grupo refere-se às questões relacionadas ao número de participantes, às sessões semiestruturadas, à existência de um setting informal $\mathrm{e}$ à presença de um moderador que coordena $\mathrm{e}$ lidera as atividades e os participantes. $\mathrm{O}$ termo focal é designado pela proposta de coletar informações sobre um tópico específico. A coleta de dados ocorreu no mês de maio de 2014. As falas dos participantes do grupo focal foram gravadas em MP3, após estes ouvirem a leitura do Termo de Consentimento Livre e Esclarecido e darem sua autorização ${ }^{10}$.

O grupo focal foi conduzido a partir das seguintes temáticas: a) entendimento do grupo sobre intersetorialidade; b) importância da intersetorialidade no contexto da ESF; c) ações realizadas na ESF compreendidas como intersetoriais; d) elementos facilitadores e dificultadores de ações intersetoriais no âmbito da ESF; e, por fim, e) sugestões para potencializar a realização de ações intersetoriais na ESF.
Para organização, análise e interpretação das falas apreendidas no grupo focal, utilizamos a Técnica do Discurso do Sujeito Coletivo (DSC). Este método, na prática, consiste na união, num só discurso-síntese, de vários discursos individuais emitidos como resposta a questões de pesquisa, por sujeito social e institucionalmente equivalente ou que faz parte de uma mesma cultura organizacional e de um grupo social homogêneo, na medida em que os indivíduos que fazem parte deste grupo ocupam a mesma ou posições vizinhas num dado campo social ${ }^{10}$.

A técnica consiste basicamente em analisar o material verbal coletado em pesquisas que têm depoimentos como sua matéria-prima, extraindo-se de cada um destes as Ideias Centrais ou Ancoragens e as suas correspondentes Expressões Chave. Com Ideias Centrais/Ancoragens e Expressões Chave semelhantes compõe-se um ou vários discursos-síntese que são os Discursos do Sujeito Coletivo ${ }^{11}$.

Outra ferramenta utilizada para auxiliar a análise dos dados foi a técnica nuvem de palavras (ou "nuvem de texto"), criada a partir do software WordleTM. Esta pode ser compreendida como uma forma de visualização de dados linguísticos, que mostra a frequência com que as palavras aparecem em um dado contexto ${ }^{12}$. A técnica de construção destas nuvens (tag clouds) consiste em usar tamanhos e fontes de letras diferentes de acordo com as ocorrências das palavras no texto analisado, gerando uma imagem que apresenta um conjunto de palavras, coletadas do corpo do texto e agregadas de acordo com sua frequência, sendo que a que mais aparece é alocada no centro da imagem e as demais em seu entorno, de modo decrescente.

Salienta-se que para as imagens geradas neste artigo, e também palavras como artigos, preposições, locuções adverbiais e outras que não apresentariam relevância de conteúdo, foram excluídas para a obtenção de um resultado conciso na conformação dos DSC. Acredita-se que a aplicabilidade do método contribui para a visualização do que é mais relevante nas falas dos participantes do estudo.

Neste estudo, foram respeitados os aspectos éticos e as implicações legais, de acordo com a Resolução No. 466/2012 $2^{13}$ do Conselho Nacional de Saúde (CNS), que aprova as diretrizes e as normas reguladoras da pesquisa envolvendo seres humanos. A execução da pesquisa foi ainda respaldada pelo Comitê de Ética em Pesquisa da UVA. 


\section{Resultados e discussões}

A pesquisa tinha em seu escopo a pretensão de produzir informações a partir das vivências e das percepções de sujeitos, com níveis distintos, mas consistentes, de engajamento na ESF em relação à questão da intersetorialidade, com foco na ESF. Optou-se por organizar aqui a análise tomando em consideração 5 pontos centrais, já identificados na metodologia, que funcionaram como catalisadores da discussão/reflexão.

Percebe-se o caráter polissêmico ${ }^{14}$ e multifacetado que a categoria intersetorialidade assume sob a perspectiva dos diferentes sujeitos envolvidos na ESF. Quando perguntados sobre qual o entendimento do grupo acerca da intersetorialidade, ou seja, como é que eles a compreendem, seus conceitos, ideias e percepções, observa-se que as respostas proporcionaram a conformação do seguinte Discurso do Sujeito Coletivo (DSC), aqui abstraído:

... um trabalho ligado, articulado com outros setores. Cada setor agregando saber ao saber do outro. Vários setores que se organizam, se articulam, cada um com sua função, com sua contribuição, para formar um plano, montar estratégias pra alcançar um resultado esperado. É abrir mão daquilo que eu planejo isoladamente, pra planejar junto. Para que a intersetorialidade aconteça de fato é preciso que os setores programem juntos. É pensar a partir da dimensão da integralidade do cuidado. É a contribuição de cada setor articulado com a qualidade de vida do indivíduo e da comunidade, na perspectiva do conceito ampliado de saúde.

Para esse coletivo, a intersetorialidade pressupõe desenvolver ações articuladas e integradas que produzam impactos positivos nas condições de vida dos indivíduos e das comunidades. Estas ações devem envolver a articulação de saberes e experiências diversas, objetivando planejar em conjunto para intervir de maneira efetiva nas situações-problema que afligem as comunidades.

Analisando esse DSC “A”, percebe-se que para os sujeitos trabalharem de forma intersetorial é preciso o compartilhamento de conhecimentos e ações visando à abordagem de novos conceitos e, consequentemente, de diferentes práticas em prol da melhoria da qualidade de vida da população. Além disso, é interessante observar que um setor isolado é limitado na solução das situações de adversidades e que a ação conjunta pode gerar um cuidado mais integral e resolutivo, fato que traz inúmeros benefícios para a população.

Entretanto, é importante que todos os profissionais estejam dispostos a atuar nessa visão de trabalho, sendo necessárias mudanças na organização dos serviços, além de revisões nos processos de formação dos profissionais atuantes na saúde.

Nesse sentido, a intersetorialidade constitui numa nova forma de trabalhar, de governar e de construir políticas públicas que possibilitem a superação da fragmentação dos conhecimentos e das estruturas sociais, a fim de produzir efeitos mais significativos na resolução desse problema ${ }^{15}$.

Como um processo coletivo e organizado, a ação intersetorial não pode ser espontânea. Trata-se de uma ação deliberada que requer o respeito à diversidade $e$ às particularidades de cada setor ou participante. Envolve espaços comunicativos, capacidade de negociação e intermediação de conflitos para a resolução ou o enfrentamento final do problema principal, como também para a acumulação de forças na construção de sujeitos e na descoberta da possibilidade de agir ${ }^{16}$.

Seguindo essa lógica, o coletivo aponta também que cada setor compõe uma rede de ação social, que deve articular-se solidariamente para identificar os problemas e encaminhar soluções integradas.

Outra dimensão/vivência que está implícita no DSC "A" diz respeito ao trabalho interdisciplinar, que significa a interação existente entre duas ou mais disciplinas, em contexto mais coletivo, no qual cada uma é, por sua vez, modificada e todas passam a depender claramente das outras. Esse processo resulta em enriquecimento recíproco e na transformação de suas metodologias de pesquisa e de seus conceitos ${ }^{17}$.

Finalmente, depara-se com a percepção bastante pertinente acerca do planejamento que a princípio poderia estranhar sua presença na discussão sobre intersetorialidade, porém as falas sugerem a necessidade de não só adotar a ferramenta do planejamento, mas que, ao fazê-lo, o mesmo deve garantir a dimensão da participação, do fazer junto, do envolvimento dos diferentes coletivos que participam do setor saúde como, por exemplo: trabalhadores, usuários, gestores $\mathrm{e}$ controle social.

O resultado gerado pela técnica "nuvem de palavras" corroborou as análises supracitadas. De acordo com a Figura 1, as palavras "Setores", "Articulado", "Saber" e "Contribuição", foram as mais importantes do discurso.

Ao avançar sobre esse discurso plural acerca da intersetorialidade, descortina-se um universo de significados muito rico. Emprestam-se diferentes metáforas na tentativa de apanhar algumas das possíveis dimensões desta realidade. É 


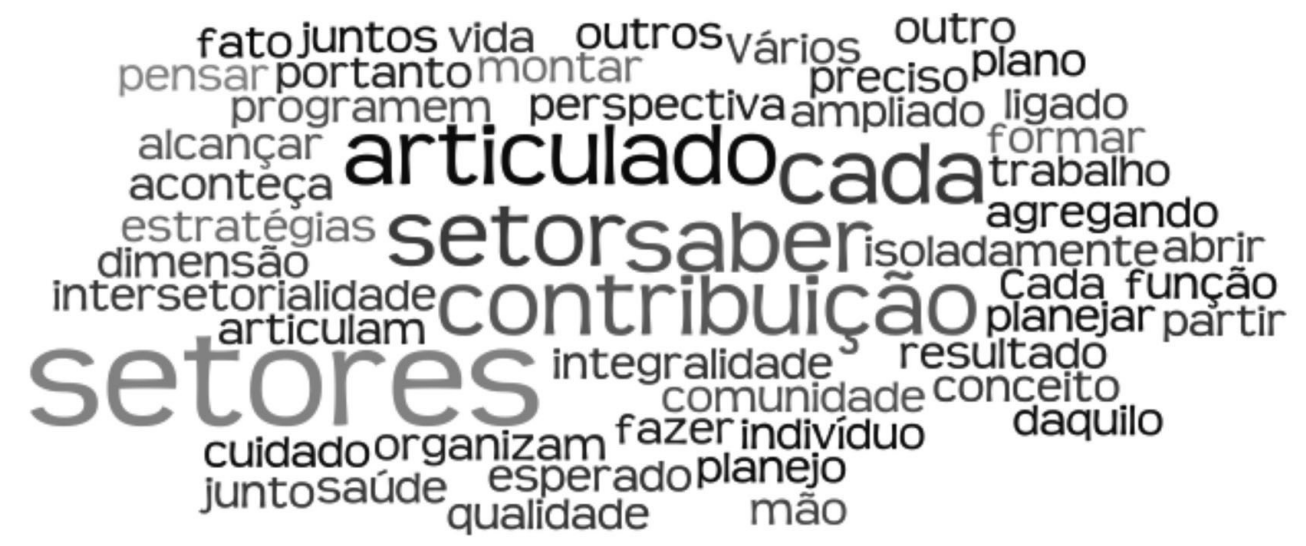

Figura 1. Nuvem de palavras elaborada com base no DSC "A" sobre o conceito de intersetorialidade. Sobral, maio de 2014.

nesse sentido que, ao serem indagados sobre a importância da intersetorialidade, no contexto da Estratégia Saúde da Família, as respostas levaram ao DSC "B" a seguir abstraído:

A intersetorialidade é indispensável na Estratégia Saúde da Família, considerando que o fazer saúde não se faz só. Para desenvolver a promoção da saúde e prevenção de doenças, tudo perpassa outras secretarias, outros espaços, outros setores, levando em consideração os determinantes sociais do processo saúde-doença. A intersetorialidade convida as políticas públicas, os setores, as pessoas a irem além daquilo que imaginam que possam contribuir para a saúde integral da população. É um convite à ação para ir além do mínimo. Para tanto, entender e conhecer o território, é condição indispensável para agir de forma intersetorial. Além disso, manter um diálogo permanente e se responsabilizando pelo cuidado do sujeito/comunidade. É entender que juntos somos mais fortes e potentes que isolados. Então, hoje em dia, o trabalho intersetorial é fundamental para a Estratégia Saúde da Família. A intersetorialidade se concretiza nessa rede de apoio, nesse segurar de mãos, pra que a gente possa realmente enfrentar dificuldades.

Observa-se que a intersetorialidade constitui uma concepção que deve desencadear uma nova maneira de planejar, executar e controlar ações e serviços para garantir acesso e qualidade da atenção à saúde de modo integral. Para isso, administradores, gestores, profissionais e até mesmo a população passam a ser considerados sujeitos com a capacidade de perceber seus problemas de maneira integrada e de identificar soluções colaborativas adequadas à realidade social. A população passa a não ser objeto de intervenção, mas, sim, um sujeito ativo assumindo um papel decisivo. Assim, muda-se a lógica da política social, saindo da visão da carência, da solução de necessidades para a de direitos a uma vida digna e com qualidade ${ }^{18}$.

Essa reflexão remete as discussões no âmbito da promoção da saúde, quando entre outros aspectos coloca-se no debate da saúde a questão dos determinantes sociais e a necessidade de se adotar uma perspectiva ampliada de saúde ${ }^{19}$.

Vemos também a percepção acerca da necessidade de se trabalhar de forma conjunta em contraposição ao modelo hegemônico de se fazer sozinho. Evidencia-se nas falas a compreensão da importância do envolvimento de vários atores e segmentos na resolução dos problemas de saúde. Estes não competem apenas aos profissionais da saúde. Outros setores e profissionais precisam envolver-se para que soluções satisfatórias sejam possíveis.

O resultado gerado pela técnica "nuvem de palavras" ratificou as análises supracitadas. De acordo com a Figura 2, as palavras que gravitaram em torno da palavra intersetorialidade com mais destaque foram: "Indispensável", "Saúde”, "Estratégia” e "Família”.

Em relação a como o grupo identifica na sua rotina de trabalho, no contexto da Estratégia Saúde da Família, ações intersetoriais, obteve-se o DSC "C". 


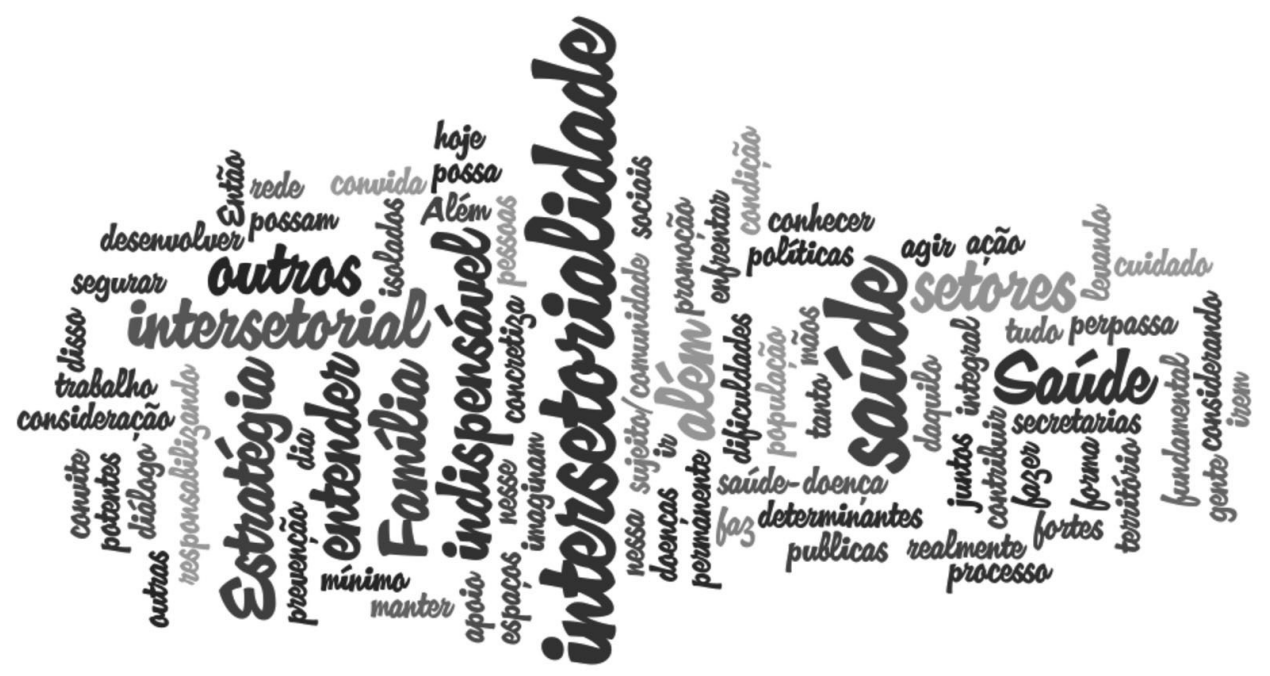

Figura 2. Nuvem de palavras elaborada com base no DSC "B" sobre a importância da intersetorialidade no contexto da Estratégia Saúde da Família. Sobral, maio de 2014.

A primeira delas é o Programa Saúde na Escola, que dialoga saúde e educação. Outra são os Projetos Terapêuticos Singulares que se fazem nas situações de risco, especialmente com gestantes, crianças, idosos, onde a gente conta com os CRAS, escolas, Secretaria de urbanismo. A política local de combate à extrema pobreza trabalha na perspectiva intersetorial. Existe um comitê técnico que envolve saúde, educação, urbanismo, saneamento básico e a Estratégia Saúde da Família... Uma atividade muito importante e que teve muita ação intersetorial foi a caminhada da paz, para discutir a questão da violência. Foram feitas reunião com vários setores, as escolas, os grupos comunitários, o comércio, as igrejas. A gente sentou, reuniu e foi uma articulação de rede... Em período chuvoso, as pessoas ficam em situação de risco, a gente precisa de um trabalho muito próximo da secretaria de educação, com a defesa civil. Tem um projeto onde são realizadas feiras nos bairros pra valorização das potencialidades locais. Outro ponto é a questão dos mutirões da dengue. Então, a gente se articula bastante com a secretaria do meio ambiente. E também ultimamente os setores de infraestrutura e urbanismo e saneamento também estiveram presentes nas unidades de saúde... Outra iniciativa foi pra trabalhar a coleta seletiva do lixo, ... Outra ação são os grupos de idosos e de gestantes desenvolvidos de maneira intersetorial, principalmente com os CRAS, ... E tem grupos de adolescente ar- ticulado com a educação. O torneio de futebol que está acontecendo,... Tem o grupo de farmácia viva e terapia comunitária com o CAPS. A semana do bebê foi uma articulação intersetorial protagonizada pelo Trevo de Quatro Folhas, em parceria com hospitais, com o Conselho Tutelar, com o Ministério Público, com os CRAS, com o CREAS.

Interessante neste momento da pesquisa, que remete necessariamente a certa objetividade, quando se demanda a identificação de ações intersetoriais, é ter por parte dos sujeitos o relato de várias situações percebidas como que se encaixam no perfil previsto para a intersetorialidade.

O discurso dos sujeitos indica uma compreensão da intersetorialidade enquanto prática inserida no fazer dos mesmos no contexto da ESF. Observa-se que as falas trazem com bastante propriedade essa prática. Várias situações são indicadas denotando que as colaborações entre diferentes segmentos é algo observável no ambiente do sistema de saúde de Sobral. Dentre os contextos institucionais onde se pôde constatar práticas colaborativas, verificam-se, aqui com certa regularidade, os setores da educação e da assistência social. Outros segmentos aparecem de forma mais pulverizada, mas não menos importante em termos de contribuição para um fazer que tenta romper com ações isoladas.

Outro ponto a ser observado é que, quando se fala em ação intersetorial, as parcerias firmadas 
permeiam desde setores/instituições públicas, até igrejas e associações comunitárias e as participações comunitárias, embora a ênfase esteja no âmbito do setor público.

Entretanto, uma questão que precisa ser colocada é até que ponto tais ações colaborativas, de cunho multisetorial, se constituem de fato em práticas intersetoriais? Estas entendidas enquanto fluxo de ação-reflexão que implicam reciprocidade e planejamento, desenvolvimento e avaliação conjunta.

O resultado gerado pela técnica "nuvem de palavras" traz mais elementos que contribuem para ajudar a reconhecer que o cenário de análise aqui desenvolvido é de fato um território multifacetado e semanticamente muito rico. De acordo com a Figura 3, a seguir, as palavras com mais destaque foram: "Educação", "Urbanismo", "Grupos", "CRAS”, "Secretarias", "Idosos", "Gestantes”, "Escolas", sendo estes os setores e segmentos que mais aparecem nas ações ditas intersetoriais.

Considerando as contradições e os tensionamentos para a implementação da intersetorialidade, o grupo foi convidado a refletir num mesmo movimento sobre o que dificulta e o que facilita o desenvolvimento de ações intersetoriais no âmbito da ESF de uma forma mais efetiva, onde se chegou ao DSC "D", a seguir:

A gente percebe que estas ações intersetoriais elas funcionam de forma muito pontual, a cada ação se chama, se convida, tem uma participação, existe um apoio. Todas as pessoas dos setores, eles têm essa boa vontade de cooperar e de apoiar. Mas assim, a gente não percebe algo mais efetivo e sistemático, como por exemplo, avaliar junto uma ação. Se foi intersetorial, por que que não existe essa corresponsabilização de planejar junto, de avaliar junto, de fazer junto? Outra coisa é a questão da burocracia. Às vezes você liga pro setor, ai tem que mandar um ofício, tem que ligar não sei pra quem, tem que pedir a autorização de outra pessoa, tem que encaminhar o caso para outro setor e aí você fica aguardando retorno que às vezes nunca chega. Muito também é a falta de diálogo, de conversa. Eu acho que essa reflexão me parece que ela foi muito sufocada até pelos próprios gestores. Eu penso que $o$ ideal de sociedade de mostrar resultado, infelizmente isso acaba minando um pouco algumas possibilidades de trabalho intersetorial. Outra grande dificuldade é essa questão da fragmentação dos

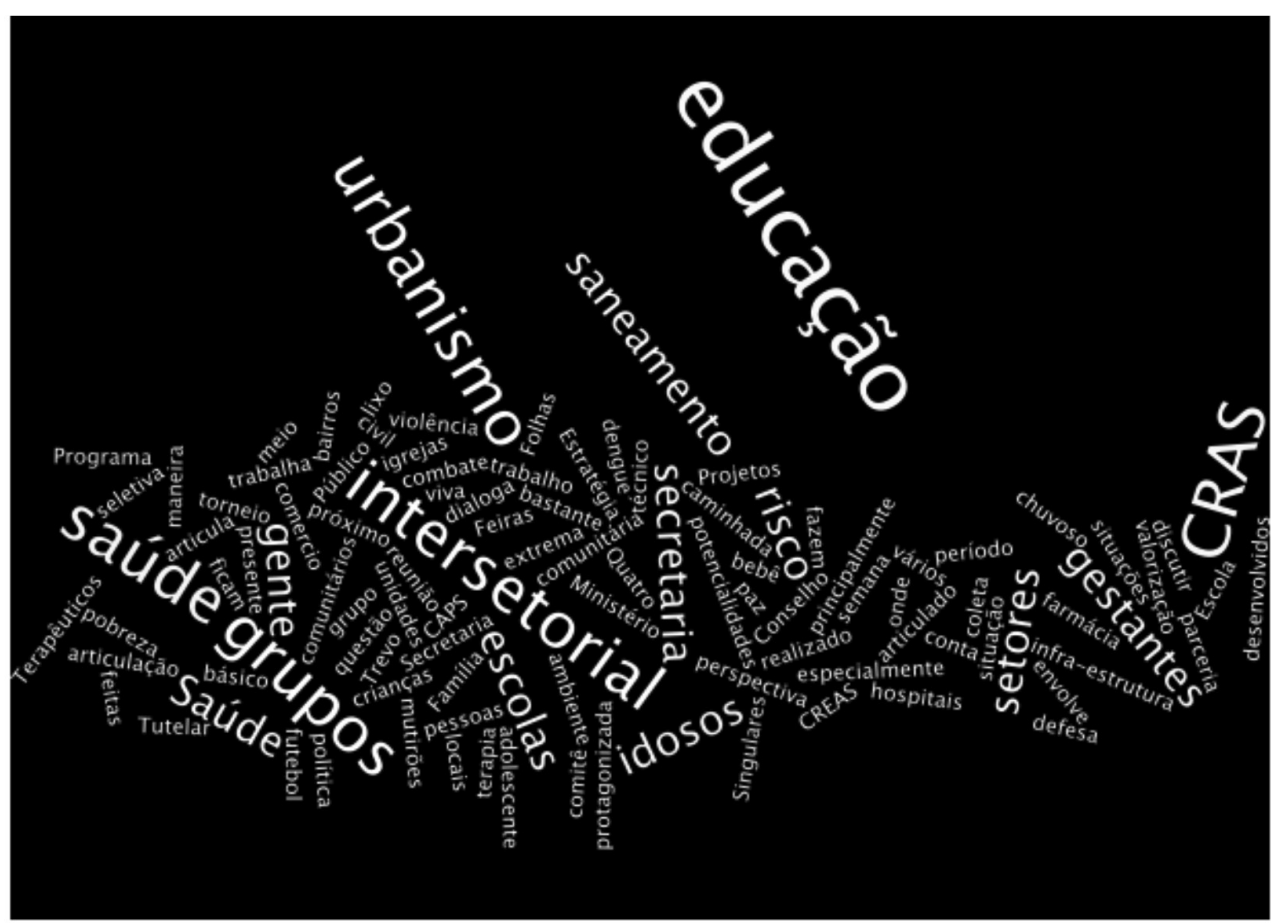

Figura 3. Nuvem de palavras elaborada com base no DSC "C" sobre as ações intersetoriais no contexto da Estratégia Saúde da Família. Sobral, maio de 2014. 
processos de trabalho. Uma situação dessas, que é muito clara, é a do Agente Comunitário de Saúde $e$ do Agente de Controle de Endemias quando um diz: não isso aqui não é meu papel, esse aqui é papel do outro.

O grupo traz uma série de questões que, de forma direta e indireta, acabam comprometendo o conceito e o desenvolvimento da intersetorialidade. Entre estas questões, destacam-se ações pontuais que são desenvolvidas de forma assistemática e, portanto, acabam comprometendo, a médio e longo prazos, o envolvimento e a corresponsabilidade dos diversos atores e instituições. Nesta mesma direção, sinalizam ainda a forte tendência ao isolamento dos setores que se acomodam nesta organização, fato que reforça a fragmentação das ações. Outra questão fundamental passa pelo corporativismo de pessoas e organizações, fato que não contribui para a construção efetiva de uma visão e de práticas pautadas na colaboratividade, na reciprocidade e na corresponsabilidade, enfim, no fomento da intersetorialidade.

Além desses aspectos, foi relatada como obstáculo, a falta de respostas dos setores aos problemas ou solicitações que lhes são encaminhados, entendendo como desinteresse às suas solicitações. A excessiva burocracia também foi considerada um fator dificultador para o processo de trabalho intersetorial na ESF.

Sobre este aspecto, Inojosa ${ }^{20}$ se posiciona que a forma como o aparato governamental se estrutura "é um elemento determinante para a qualidade dos produtos ou serviços que o Estado entrega à sociedade [...]". Para esta autora, as estruturas organizacionais se apresentam de forma "piramidal", com "vários escalões hierárquicos", "departamentalizados por áreas de especialidades", desenvolvendo-se neste contexto diversas formas de organizar o trabalho, tais como: "centralização decisória, planejamento normativo, dicotomia entre planejamento e execução, sigilo e ocultação de informações, formalização excessiva, e distanciamento do cidadão e mesmo do usuário, dificultando o controle social".

Percebe-se, portanto, que o discurso acerca da intersetorialidade, a exemplo do que acontece com a interdisciplinaridade, tem sido mais desenvolvido que sua prática, havendo muita dificuldade em mudar o modelo de gestã $0^{21}$. O discurso da colaboração defende que os atores, por serem iguais, podem exercitar uma colaboração mútua, porém "a lógica da parceria", implica na ideia de "conflito", devido à existência de uma diversidade de condições estruturais destes ato- res, que envolvem acesso a recursos financeiros, informação ou poder. Portanto, a intersetorialidade é um processo complexo, que implica em enfrentar "contradições, restrições e resistências". A intersetorialidade exige uma mudança da "lógica de governo, de organização do trabalho para a prevenção ou solução de problemas existentes em um território geográfico, e não em setores específicos como vem ocorrendo [...]"21.

Quando você tem um profissional comprometido e ele sai do individualismo e amplia a visão pro coletivo, se responsabiliza com o território, e vai muito além. Seria o planejar junto, seria o consenso que é importante, o que é que é o nosso objetivo. É conhecer o que é o papel do outro, o que é o meu papel, até onde eu posso entrar no espaço do outro e o outro no meu, pra que não haja esses conflitos e nem o egocentrismo de eu ficar no meu espaço olhando os meus problemas e resolvendo somente os que acho que são meus. Dialogar, chegar a consensos, planejar, avaliar junto o impacto dessas estratégias, desse diálogo, desse trabalho junto. Os conselhos locais podem ser estratégicos, uma vez que muitas articulações são feitas neste âmbito. O orçamento participativo, momento que o prefeito foi até às comunidades levando vários setores pra ouvir as demandas da comunidade. Por isso, que eu falo muito no diálogo. É também estar indo atrás e não ficar só esperando que eles venham até a gente e que as coisas vão acontecer, sem a gente ir atrás e conversar.

Por outro lado, quando se examina as falas que indicam os possíveis elementos facilitadores em relação à intersetorialidade no âmbito da ESF, constata-se a presença em destaque dos seguintes fatores: compromisso do profissional com a ESF, visão do coletivo e não apenas da parte, responsabilização com o território, conhecimento das atribuições dos outros setores e profissionais, a capacidade de dialogar e, ainda, a experiência vivenciada na prática do orçamento participativo no cenário do município de Sobral.

Foi observado a partir das facilidades relatadas, que, mesmo a intersetorialidade dependendo de uma política mais geral, existem algumas iniciativas que funcionam, quando estas ações são desenvolvidas permeadas pelo diálogo e consensos, sobressaindo as realizadas com a participação popular a exemplo dos Conselhos Locais de Saúde e do Orçamento Participativo.

$\mathrm{O}$ resultado gerado pela técnica "nuvem de palavras" confirma as análises supracitadas. De acordo com a Figura 4, as palavras que gravitam entorno da palavra intersetorialidade com mais destaque foram: "Gente", "Educação", "Grupos", "Articulação", "Diálogo", "Individualismo". 


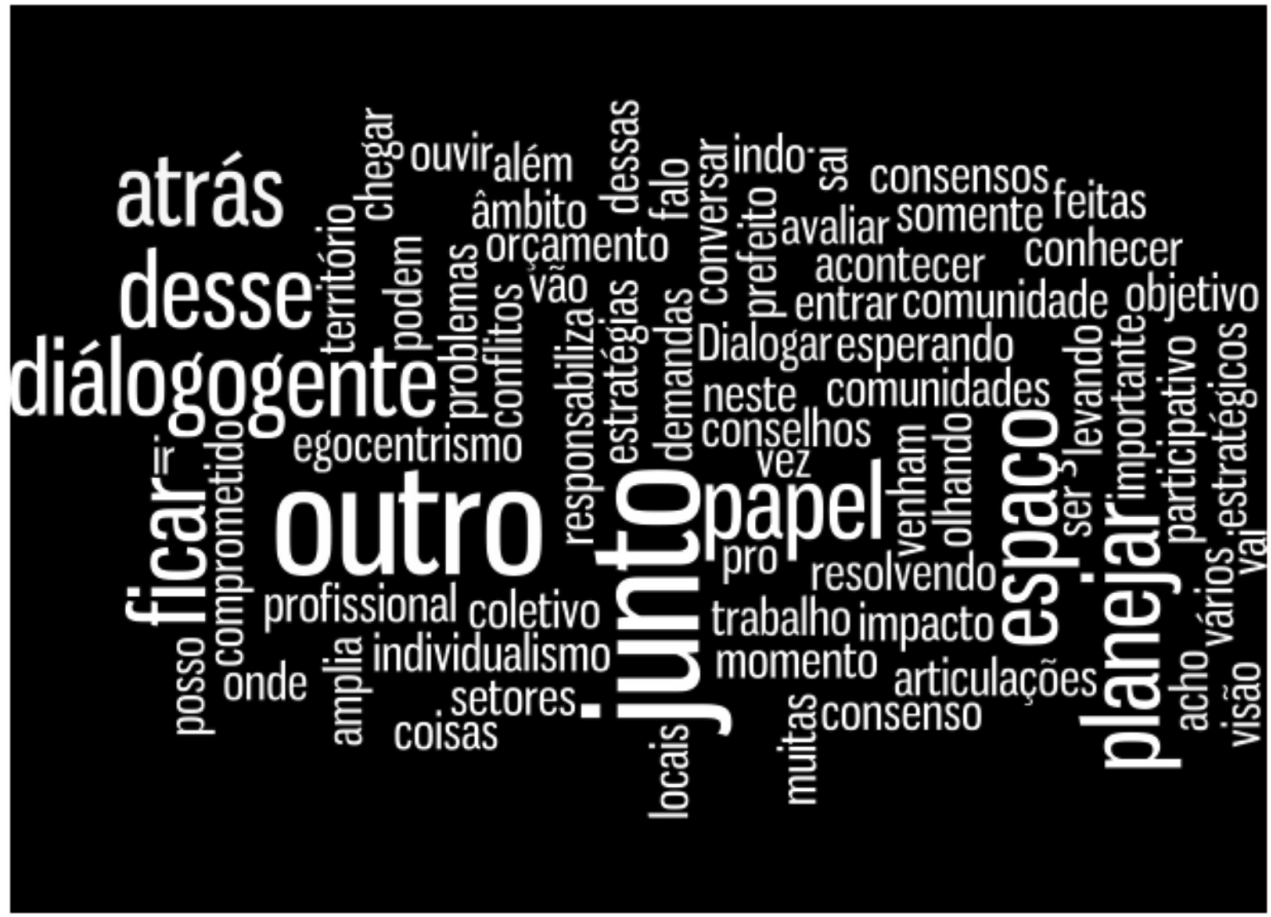

Figura 4. Nuvem de palavras elaborada com base no DSC “D” e "E”. Dificultadores e Facilitadores para desenvolver ações intersetoriais no contexto da Estratégia Saúde da Família. Sobral, maio de 2014.

Os dados sugerem, como se vem descobrindo neste e em outros estudos, que a intersetorialidade é algo que remete a um novo paradigma. Tradicionalmente tem prevalecido o modelo fragmentado e dicotômico bastante característico da visão mecanicista da saúde. Mas, quando se pensa numa dimensão ampliada de saúde e na questão da integralidade, é necessário passar do paradigma tradicional para o sistêmico. Portanto, implica adotar-se uma nova perspectiva de trabalhar e enfrentar os problemas que passam, entre outros, por assumir uma das premissas da intersetorialidade que seja, o de trabalhar junto, envolvendo os diferentes segmentos no enfrentamento dos problemas de saúde.

É, portanto, fundamental avançar para o desenvolvimento de projetos intersetoriais, que tragam de fato o compromisso com ações de promoção da saúde e melhoria da qualidade de vida para a lógica da corresponsabilização, que articulem além da saúde, outros setores das políticas públicas ${ }^{22}$.

Reconhece-se aqui que outros estudos ${ }^{21-23}$ apontam para uma compreensão da intersetorialidade como algo ainda em movimento, em cons- trução, inacabada. E que a vivência da mesma não é simples por vir acompanhada de contradições e tensionamentos, por envolver diferentes segmentos e atores sociais.

Por fim, procurou-se levantar sugestões/indicações do grupo no sentido de melhorar ou potencializar as práticas intersetoriais no contexto da Estratégia Saúde da Família, a partir da experiência e conhecimento do mesmo. O que deveríamos fazer? Obteve-se o seguinte DSC "F":

Acho que a primeira coisa era: se a gente dentro de cada território tivesse um comitê intersetorial que trabalhasse dentro desse comitê as prioridades daquele local. Um colegiado intersetorial, de forma que a gente tivesse representantes de todas as potencialidades, que tinham dentro daquele território para discutir as prioridades daquele bairro, daquele território e planejar junto e fazer junto. Eu acho que aí sim, talvez a gente conseguisse sucesso, bem mais sucesso nas ações. Inclusive dentro dessa ação intersetorial envolver a comunidade, por que ela também tem potencial e precisa ser envolvida, dentro desse comitê. Então, assim, eu acho importante que a gente comece a pensar nesses pactos, nesses colegiados intersetoriais. Mas que eles não 
sejam somente aquele momento, que ele também tenha um direcionamento de gestão. A gestão devia trazer um posicionamento desta opção pela intersetorialidade e que isso configurasse como uma diretriz nas políticas públicas. As ações para se tornarem intersetoriais elas precisam se capilarizar, pra que a gente possa difundir mais a ideia do que cada setor está trabalhando e se aproximar realmente.

A intersetorialdade diz respeito a uma prática e a uma visão que remetem a dimensão do complexo $^{4}$, isso quer dizer que são múltiplos os determinantes presentes como, por exemplo, questões sociais, políticas e culturais. Tradicionalmente, $o$ paradigma baseado na fragmentação da realidade tem sido hegemônico. Entretanto, quando se pensa hoje na própria definição de saúde constata-se que, a partir do conceito ampliado, não é possível apenas ao setor saúde isoladamente dar conta dos muitos desafios.

Ao analisarmos as sugestões apresentadas pelo grupo, indicando possíveis estratégias que potencializam a intersetorialidade no campo da saúde, destacam-se os seguintes aspectos: a constituição de um comitê ou colegiado para gestão e promoção da intersetorialidade, a prática do planejamento participativo, o envolvimento da comunidade, que seja algo permanente e não apenas pontual em função de algum projeto, que se assuma a intersetorialidade como uma diretriz política de gestão pública, não só no âmbito da saúde, mas de outros ambientes da gestão pública.

Percebe-se nas falas dos profissionais da ESF que estes reconhecem que sozinhos não conseguirão promover as mudanças desejadas rumo à efetivação da intersetorialidade na ESF, visando à promoção da Saúde. Esta constatação vem confirmar o já previsto por $\mathrm{Mendes}^{24}$, que as equipes da Estratégia da Saúde da Família, por estarem hierarquicamente em um nível inferior dos setores implicados na resolução dos problemas identificados, teriam seus esforços integrativos limitados, pois estes estariam na dependência das "capacidades de condução de níveis superiores", daí que torna-se necessário que se configure como política de governo e não de um setor específico.

O resultado gerado pela técnica "nuvem de palavras" confirma as análises supracitadas. De acordo com a Figura 5, as palavras que gravitam entorno do conceito intersetorialidade com mais destaque são: "Gente”, “Gestão”, “Comitês”, "Junto”.

\section{Conclusão}

A questão da intersetorialidade potencializa e se relaciona de muitos modos com os propósitos da ESF, ao adotar como princípios a integração de vários saberes e setores, proporcionando uma

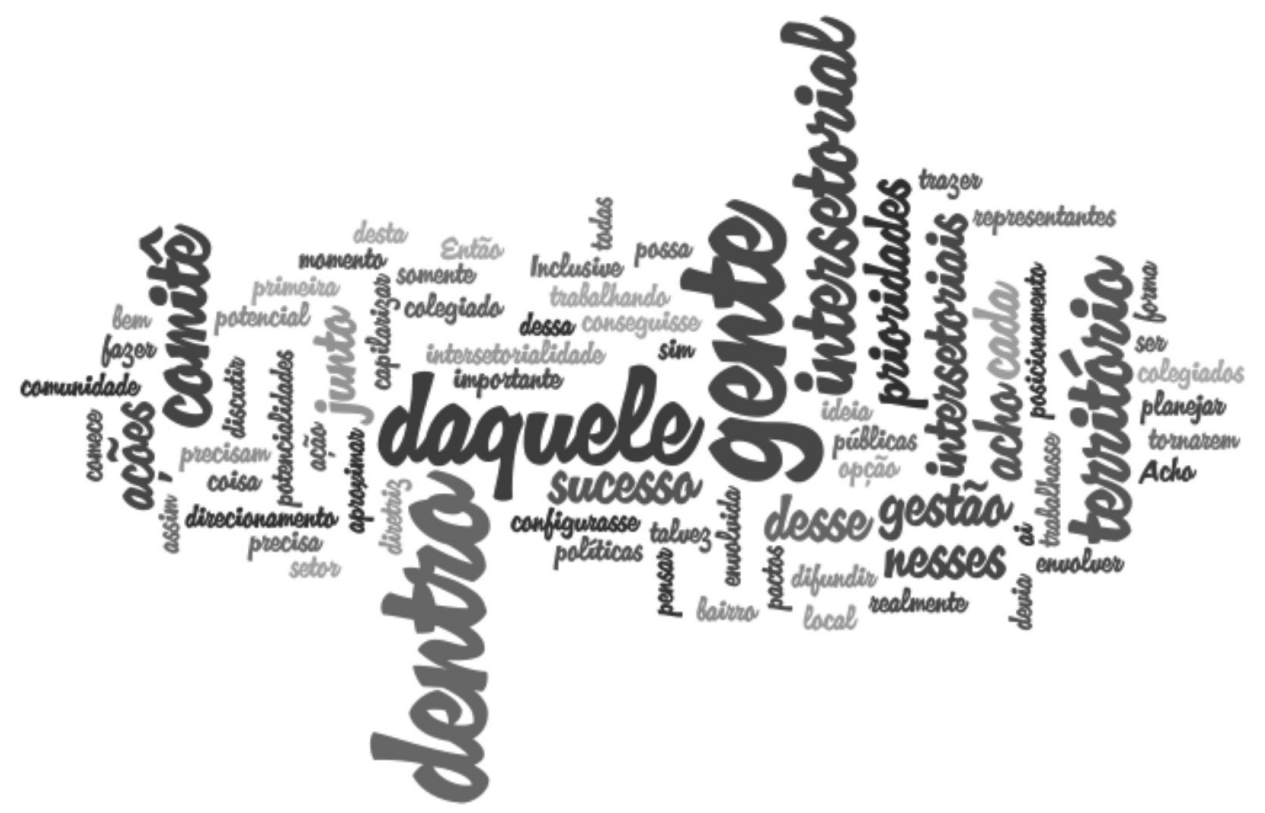

Figura 5. Nuvem de palavras elaborada com base no DSC F. Sugestões para potencializar ações intersetoriais no contexto da Estratégia Saúde da Família. Sobral, maio de 2014. 
percepção mais abrangente da realidade e dos processos de saúde.

Este estudo pôde reconhecer as dificuldades e os potenciais das iniciativas que buscam trabalhar a saúde a partir de uma nova agenda, com um fazer colaborativo e solidário envolvendo distintos segmentos e pessoas. Dando sinais, bem relevantes, de que a intersetorialidade é possível.

De fato, os dados colhidos e analisados neste estudo confirmam que a intersetorialidade tem tudo a ver com a ESF, ao considerar entre as prioridades desta a reorientação das práticas de saúde, a centralidade do território, o agir focado nas necessidades de saúde, a promoção de ações integrais, o avaliar e o pesquisar contínuo ${ }^{25}$ e o fomento às estratégias de fortalecimento da gestão local e do controle social. Portanto, compreendese que a intersetorialidade é e será determinante para uma vivência efetiva da ESF.

Pode-se afirmar sobre a intersetorialidade que, apesar do reconhecimento de sua potência, ainda enfrenta muitos obstáculos. Estes passam principalmente pela fragmentação e isolamento das ações no campo da saúde. A superação e o consequente fortalecimento da intersetorialidade residem, entre outros aspectos, na adoção de uma visão sistêmica acerca da realidade. No caso parti- cular da saúde, o próprio conceito ampliado desta passa a ser um incentivador para o trabalho cooperativo entre diferentes setores, tanto no plano interno dos serviços de saúde quanto no envolvimento de outros segmentos para além do tradicional setor saúde, como é o caso da educação.

Finalmente, conclui-se que a intersetorialidade é uma prática em construção, que não se restringe à ESF, assim como o contrário também é verdadeiro. Porém, há uma relação de interdependência entre estes dois campos.

Compreende-se que dificilmente a ESF se viabilizaria sem a visão e as práticas intersetoriais, ou seja, a intersetorialidade não é apenas uma realidade transversal à $\mathrm{ESF}$, mas inerente a ela. Detecta-se aqui, a partir dos achados deste estudo introdutório, que é na ESF que a intersetorialidade encontra as melhores oportunidades para contribuir com o desenvolvimento de algo fundamental, isto é, um novo modelo de fazer e promover saúde.

Entretanto, o exercício da intersetorialidade exige não apenas o desempenho dos profissionais da ESF, sendo requerida uma política municipal, na qual todos os setores, governamentais e não governamentais, e a sociedade civil estejam direcionados ao seu cumprimento.

\section{Colaboradores}

MAS Dias, JRF Parente, MIO Cavalcante e FAC Dias participaram igualmente de todas as etapas de elaboração do artigo. 


\section{Referências}

1. Gleiser M. A dança do universo: dos mitos de criação ao big-bang. São Paulo: Cia das Letras; 2001.

2. Capra F. As conexões ocultas: ciência para uma vida sustentável. São Paulo: Cultrix, Amana-Key; 2009.

3. Morin E. Os sete saberes necessários à educação do futuro. 3a ed. São Paulo, Brasília: Cortez, Unesco; 2001.

4. Cristina AM, Fabrício F, Teixeira FMB, Suss JAC, Lawder LSM, Lima RE, Bueno SJ, Moysés ST. Intersetorialidade nas ações de promoção de saúde realizadas pelas equipes de saúde bucal de Curitiba (PR). Cien Saude Colet 2010; 15(1):1827-1834.

5. Inojosa R. Sinergia em políticas e serviços públicos: desenvolvimento social com intersetorialidade. Cadernos Fundap 2011; 22:102-110.

6. Bordenave JD. O Que é Participação? São Paulo: Editora Brasiliense; 1983.

7. Brasil. Ministério da Saúde (MS). Secretaria da Atenção Básica à Saúde. Departamento de Atenção Básica. Politica Nacional de Atenção. 4a Ed. Brasília: MS; 2007. (Série Pactos pela Saúde 2006, v.4)

8. Sobral. Secretaria da Tecnologia e Desenvolvimento Econômico. Anuário Estatístico. Sobral: Secretaria da Tecnologia e Desenvolvimento Econômico; 2013.

9. Soares CHA, Pinto VPT, Dias MSA, Parente JRF, Chagas MIO. Sistema saúde escola de Sobral (CE). Sanare Revista de Políticas Públicas 2008; 7(2):7-13.

10. Flick U. Uma introdução à pesquisa qualitativa. Porto Alegre: Bookman, 2004.

11. Lefevre F, Lefevre AMC, Marques MCC. Discurso do Sujeito Coletivo, complexidade e auto-organização. Cien Saude Colet 2009; 14(4):1193-1204.

12. Mcnaught $C$, Lam, P. Using wordle as a supplementary research tool. The Qualitative Report 2010; 15(3):630643.

13. Brasil. Ministério da Saúde (MS). Conselho Nacional de Saúde. Resolução no 466, de 12 de dezembro de 2012. Diário Oficial da União 2013; 13 jun.

14. Canada. Public Health Agency. Crossing sectors - Experiences in intersectoral action, public policy and health. Ottawa: Public Health Agency; 2007.

15. Comerlatto D, Matiello A, Colliselli L, Renk EC, Kleba ME. Gestão de políticas públicas e intersetorialidade: diálogo e construções essenciais para os conselhos municipais. Rev Katálysis 2007; 10(2):265-271.
16. Campos GWS. Um método para análise e co-gestão de coletivos. São Paulo: Hucitec; 2000.

17. Torres SJ. Globalização e interdisciplinaridade: o currículo integrado. Porto Alegre: Artmed; 1998.

18. Junqueira LAP. Descentralização, intersetorialidade e rede como estratégias de gestão da Cidade. Rev FEAPUC-SP 1999; 1:57-72.

19. Rabello LS. Promoção da Saúde, a construção de um conceito em perspectiva comparada [tese]. Rio de Janeiro: Fiocruz; 2010.

20. Inojosa RM. Intersetorialidade e a Configuração de um novo paradigma organizacional. Rev Administração Pública 1998; 32(2):35-48.

21. Westphal MF, Mendes R. Cidade saudável: uma experiência de interdisciplinaridade e intersetorialidade. Rev Administração Pública 2000; 34(6):47-61.

22. Portes LH, Campos EMS, Teixeira MTB, Caetano R, Ribeiro LC. Ações voltadas para o tabagismo: análise de sua implementação na Atenção Primária à Saúde. Cien Saude Colet 2014; 19(2):439-448.

23. Papoula SR. O processo de trabalho intersetorial das Equipes de Saúde da família no município de Petrópolis-RJ: fatores restritivos e facilitadores [dissertação]. Rio de Janeiro: Escola Nacional de Saúde Pública; 2006.

24. Mendes EV. Uma Agenda para a Saúde. 2a ed. São Paulo: Editora Hucitec; 1999.

25. Magalhães R, Bodstein R. Avaliação de iniciativas e programas intersetoriais em saúde: desafios e aprendizados. Cien Saude Colet 2009; 14(3):816-868.
Artigo apresentado em 30/06/2014

Aprovado em 12/08/2014

Versão final apresentada em 13/08/2014 